UCRL-JC-126863

PREPRINT

\title{
Effect of Microvoids on the Shock Initiation of PETN
}

\author{
J.L. Maienschein \\ P.A. Urtiew \\ F. Garcia \\ J.B. Chandler
}

This paper was prepared for submittal to the

1997 Topical Conference on Shock Compression of Condensed Matter of the American Physical Society

Amherst, MA

July 27 - August 1, 1997

July 1997

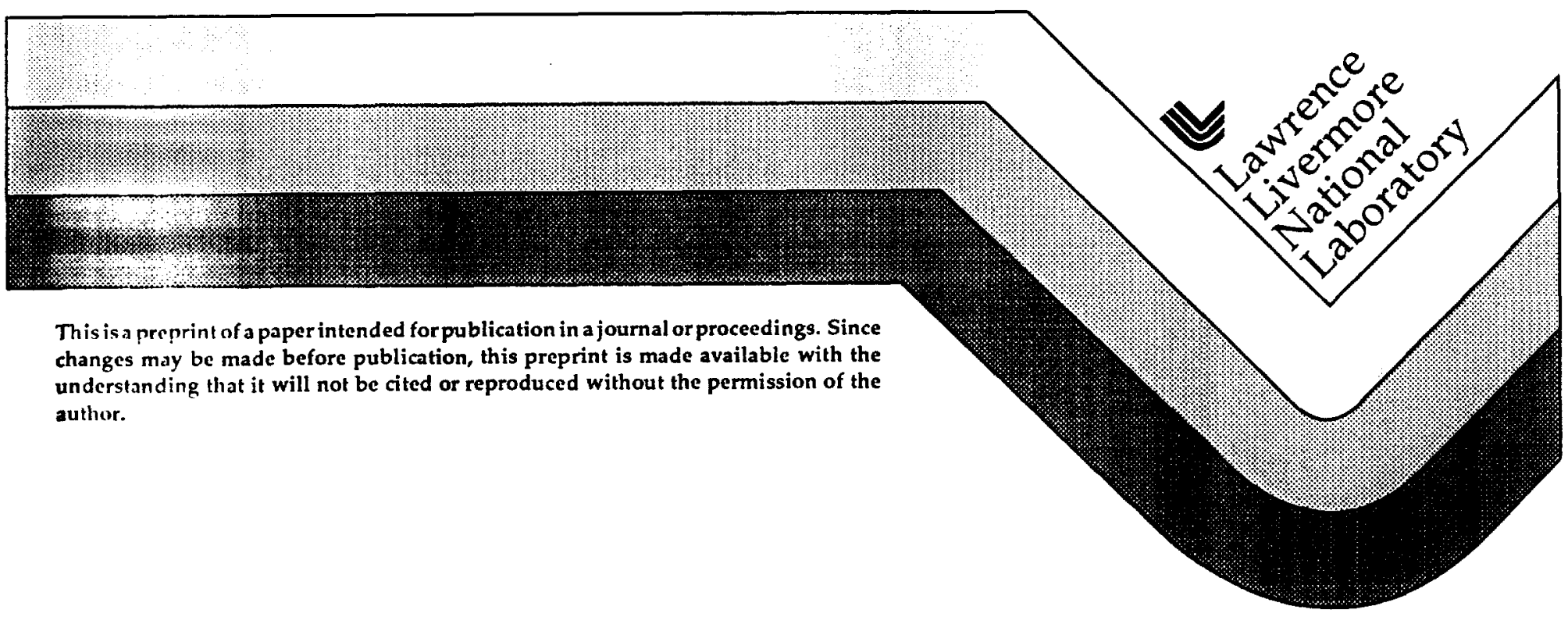




\section{DISCLAIMER}

This document was prepared as an account of work sponsored by an agency of the United States Government. Neither the United States Government nor the University of California nor any of their employees, makes any warranty, express or implied, or assumes any legal liability or responsibility for the accuracy, completeness, or usefulness of any information, apparatus, product, or process

disclosed, or represents that its use would not infringe privately owned rights. Reference herein to any specific commercial product, process, or service by trade name, trademark, manufacturer, or otherwise, does not necessarily constitute or imply its endorsement, recommendation, or favoring by the United States Government or the University of California. The views and opinions of authors expressed herein do not necessarily state or reflect those of the United States Government or the University of California, and shall not be used for advertising or product endorsement purposes. 


\title{
EFFECT OF MICROVOIDS ON THE SHOCK INITIATION OF PETN
}

\author{
J.L. Maienschein, P.A. Urtiew, F. Garcia, J.B. Chandler \\ Lawrence Livermore National Laboratory, Livermore, CA 94550
}

\begin{abstract}
We demonstrate that the introduction of microvoids as glass microballoons sensitizes high-density solventpressed PETN to shock initiation. At input pressures ranging from 1.4-2.0 GPa, shock propagation velocities are higher and run distances to detonation are shorter for PETN sensitized by microballoons. By selecting the size and density of microballoons, we can therefore study the effect of void size and density on shock initiation by hot spots.
\end{abstract}

\section{INTRODUCTION}

It is accepted that hot spots, formed by shock interaction with voids or defects in explosives, control the onset of detonation; although many mechanisms have been postulated and modeled, the actual mechanism(s) are unknown. Our goal here is to quantify the effect on initiation of variations in the density and size of defects in an explosive. These data should prove useful in theoretical considerations of hot spot mechanisms.

We added a known quantity of voids to a nearly homogeneous explosive and determined their effect on shock initiation, using a one-dimensional impact with in-situ pressure gauges. We chose pentaerythritol tetranitrate (PETN), since it is nearly ideal (no reaction zone effects) and can be solvent-pressed to a low porosity. Glass microballoons introduced into the PETN provided a controlled size and density of defects. Results here show the feasibility of this approach.

\section{PREPARATION OF SAMPLES}

PETN samples $19 \mathrm{~mm}$ in diameter and 1.5-1.7 $\mathrm{mm}$ thick were solvent pressed with acetone. Densities of $92-95 \%$ of TMD (theoretical maximum density, $1.77 \mathrm{~g} / \mathrm{cc}$ ) were achieved by pressing 0.75 grams of powdered PETN (batch B-509) with $0.2 \mathrm{cc}$ acetone in a uniaxial compaction die for
5 minutes at $200 \mathrm{MPa}$, after a 5 minutes soak at ambient pressure. A larger acetone volume of $2.0 \mathrm{cc}$, with three 5 -minute pressing periods and 1 minute recovery times between pressure cycles, increased the density to $96-97 \%$ TMD.

Glass microballoons (Q Cel 650) were separated by sieving; we used the fraction that passed through a 25 micron sieve. From a photomicrograph, diameters ranged from 4-20 microns. Wall thickness appeared to be $\approx 10 \%$ of the diameter, although this was not accurately determined. A blend of 91 volume \% PETN and 9 volume \% microballoons was stirred by hand and pressed at the first pressing conditions to produce samples with densities of $86-88 \%$ TMD. We dissolved the PETN from a sample to verify that the glass microballoons remained intact, and confirmed that very few were broken.

\section{SHOCK INITIATION EXPERIMENTS}

We measured initiation and onset of detonation in samples subjected to impact from the 102-mm gun in the High Explosives Application Facility at LLNL. Targets had 4 or 6 layers of explosive, with a manganin pressure gauge between each layer and under the polycarbonate buffer layer on the impact surface. The manganin gauges were LLNL 50 milliohm style, 25 microns thick, laminated in 50 or 130 microns of Teflon ${ }^{\circledR}$ on each side. Each 
target was impacted by a polycarbonate sabot traveling $0.59-1.1 \mathrm{~mm} / \mu \mathrm{s}$, with impact pressures of 1.1-2.5 GPa. Data included pressure/time and shock propagation velocity. More details of this type of experiment are given in reference 1 .

\section{EXPERIMENTAL RESULTS}

The shot conditions are shown in Table 1. Each of the three shots with PETN/microballoons has a matching shot with pure PETN at about the same pressure. Comparison of these pairs of shots allows determination of the effect of the microballoons on shock initiation. Shock propagation velocities (Table 1 and Figs. 1-3) show that velocity acceleration is greater in samples with microballoons than in those without. At 1.2 GPa, the velocity increases $\approx 10 \%$ over a run distance of $5 \mathrm{~mm}$ with microballoons, but does not increase until a run distance of $6.3 \mathrm{~mm}$ without microballoons. At $1.4 \mathrm{GPa}$, both samples show a velocity increase, but it is more pronounced in the sample with microballoons. At $2.0 \mathrm{GPa}$, the microballoon sample accelerates earlier to detonation velocity. Thus all shots show increased sensitivity with microballoons.

TABLE 1. Sample specifications, impact conditions, and propagation velocities observed in shock impact experiments with PETN samples with and without microballoons.

\begin{tabular}{|c|c|c|c|c|c|c|c|c|c|c|c|c|c|c|c|}
\hline $\begin{array}{c}\text { Shot } \\
\#\end{array}$ & Mat'l & $\begin{array}{c}\text { density } \\
\text { g/cc }\end{array}$ & $\begin{array}{c}\text { density } \\
\text { TMD }\end{array}$ & $\begin{array}{c}\text { impact } \\
\text { vel } \\
\mathrm{m} \mathrm{m} / \mu \mathrm{s}\end{array}$ & $\begin{array}{c}\text { impact } \\
\text { pres. } \\
\text { GPa }\end{array}$ & $\begin{array}{r}\text { shocl } \\
\text { 1st }\end{array}$ & 2nd & 3rd & 4th & $\begin{array}{l}\text { ity in } \\
5 \text { th }\end{array}$ & $\begin{array}{l}\text { total r } \\
\text { to } 1 s t\end{array}$ & to 2 nd & $\begin{array}{l}\text { nce to } \\
\mathrm{m} \mathrm{m} \\
\text { to } 3 \text { rd }\end{array}$ & to 4th & $\begin{array}{l}\text { ment, } \\
\text { to } 5 \text { th }\end{array}$ \\
\hline 4467 & PETN & 716 & $96.9 \%$ & 0.587 & 1.15 & 2.85 & 2.90 & 2.90 & 2.87 & 2.79 & 1.46 & 2.92 & 4.35 & 5.79 & 7.23 \\
\hline 4451 & $\begin{array}{c}\text { PETN } / \\
\mu \text { ball }\end{array}$ & 1.575 & $89.0 \%$ & 0.689 & 1.16 & 1.81 & 1.96 & 2.03 & & & 1.72 & 3.44 & 5.17 & & \\
\hline 4465 & PETN & 640 & $92.7 \%$ & 0.687 & 1.27 & 2.80 & 2.99 & 2.71 & 2.74 & 5.97 & 1.63 & 3.23 & 4.78 & 6.25 & 7.76 \\
\hline 4466 & PETN & 1.653 & $93.4 \%$ & 0.699 & 1.32 & 2.78 & 2.86 & 2.81 & 2.26 & 3.53 & 1.58 & 3.10 & 4.60 & 6.08 & 7.57 \\
\hline 4447 & PETN & 1.678 & $94.8 \%$ & 0.689 & 1.35 & 2.66 & 2.69 & 2.77 & & & 1.55 & 3.12 & 4.67 & & \\
\hline 4450 & $\begin{array}{c}\text { PETN/ } \\
\mu \text { ball }\end{array}$ & 1.558 & $88.0 \%$ & 0.840 & 1.45 & 2.02 & 2.33 & 3.13 & & & 1.71 & 3.40 & 5.11 & & \\
\hline 4448 & PETN & 1.685 & $95.2 \%$ & 0.850 & 1.78 & 2.76 & 3.02 & 8.33 & & & 1.55 & 3.11 & 4.68 & & \\
\hline 4452 & $\begin{array}{c}\text { PETN/ } \\
\mu \text { ball }\end{array}$ & 1.544 & $87.2 \%$ & 1.090 & 1.98 & 2.45 & 4.59 & 8.97 & & & 1.69 & 3.40 & 5.13 & & \\
\hline 4468 & PETN & 1.720 & $97.2 \%$ & 0.916 & 2.04 & 3.09 & 3.34 & 4.63 & 9.53 & 10.21 & 1.45 & 2.89 & 4.34 & 5.78 & 7.22 \\
\hline 4449 & $\overline{\text { PETN }}$ & 1.688 & $95.4 \%$ & 1.090 & 2.48 & 3.09 & 9.26 & 10.6 & & & 1.55 & 3.08 & 4.64 & & \\
\hline
\end{tabular}

Typical pressure data are shown in Fig. 4 for shot 4468 with pure PETN at $97.2 \%$ TMD and 2.0 GPa. Gauge depths are shown in Table 1 (first gauge is at buffer/PETn interface). We see slight reaction buildup at the first gauge, with more reaction at each successive gauge until the sample detonates at the 4th gauge, at a depth of $4.34 \mathrm{~mm}$.

Comparison of individual gauge records shows that the presence of microballoons sensitizes the PETN to shock. Examples are shown in Fig. 5-7 for gauges at the third and fourth location in shots at $1.4 \mathrm{GPa}$; in all cases the gauge with micro-

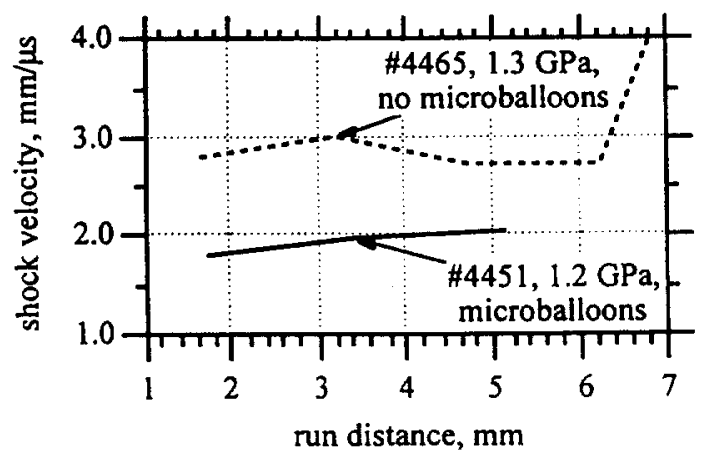

FIGURE 1. Shock propagation velocity, $1.2 \mathrm{GPa}$. 


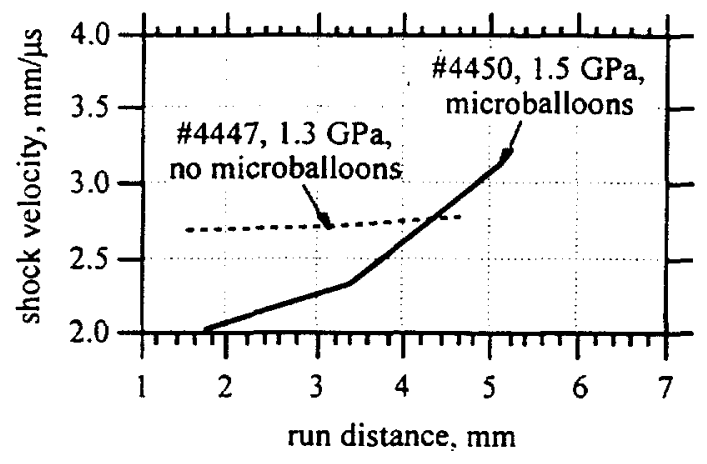

FIGURE 2. Shock propagation velocity, $1.4 \mathrm{GPa}$.

balloons is shifted in time to match onset times. In Fig. 5 the pressure at the third gauge build up faster following arrival of the shock for the microballoon sample; however, it is at a slightly longer run distance. In Fig. 6 the fourth pressure gauge shows detonation only in the sample with microballoons, but again the run distances are not strictly comparable. However, comparison of the third gauge at $3.4 \mathrm{~mm}$ run in the sample with microballoons with the fourth gauge at $4.67 \mathrm{~mm}$ run distance in the sample without microballoons shows almost identical profiles; since the gauge with microballoons is located at a shorter run distance than in the sample with no microballoons, this comparison clearly shows the increased sensitivity to initiation caused by the microballoons.

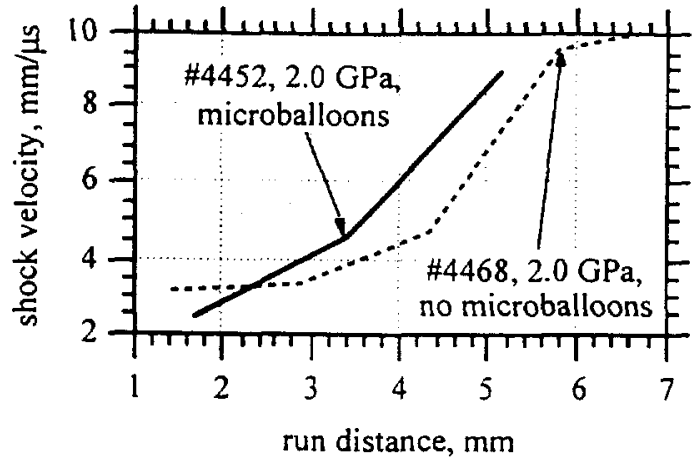

FIGURE 3. Shock propagation velocity, $2.0 \mathrm{GPa}$

\section{DISCUSSION OF RESULTS}

In our samples, the density of samples was $\approx 88 \%$ TMD with microballoons, and $\approx 95 \%$ TMD without microballoons. Therefore, the void fraction was increased from $5 \%$ to $12 \%$, or 2.5 -times, by the inclusion of glass microballoons. This was sufficient to confer increased sensitivity to shock. To achieve our original goal of quantifying the effect of different sizes and densities of voids, a few improvements are needed. The size distribution of glass microballoons was wider than desired in this work, and was not accurately characterized. The homogeneity of microballoons in the pressed parts was unknown. The density of the pressed PETN/microballoon parts was also lower than desired, since we pressed those parts early on in the

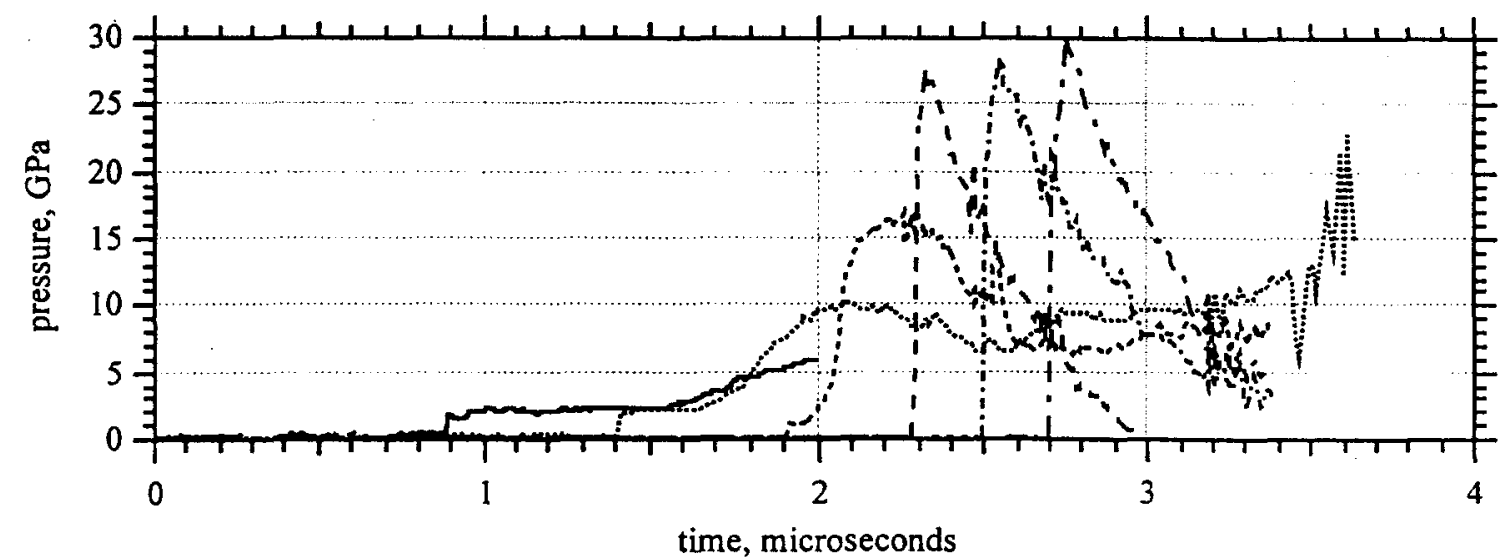

FIGURE 4. Manganin gauge pressure data in shot 4468 , pure PETN at $97.2 \%$ TMD. Input pressure is $2.0 \mathrm{GPa}$. 


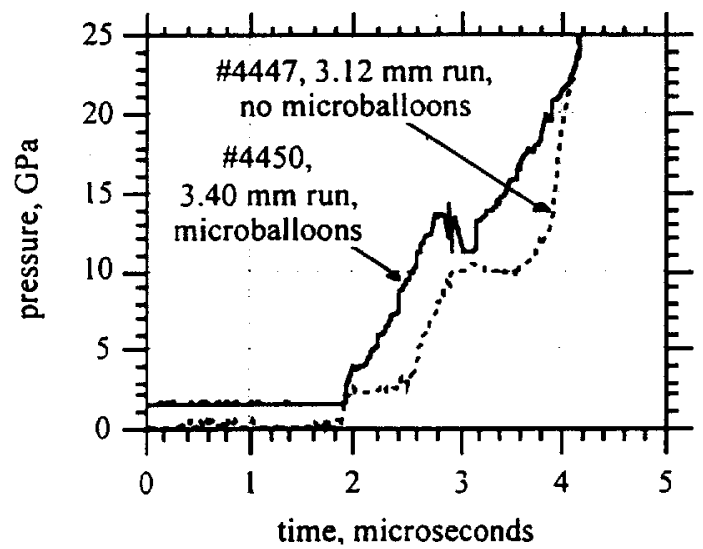

FIGURE 5. Data from the third pressure gauge, $1.4 \mathrm{GPa}$.

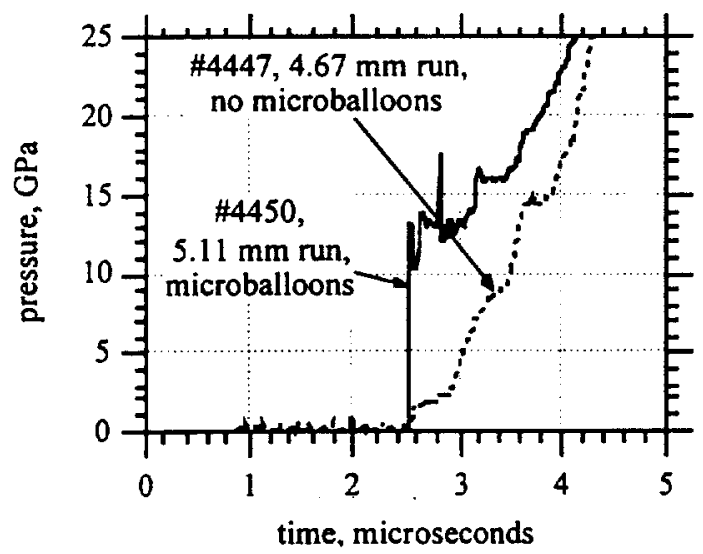

FIGURE 6. Data from the fourth pressure gauge, $14 \mathrm{GPa}$.

experimental sequence. A further limitation is the impedance mismatch between glass and explosive, which results in shock reflection in the sample which would not be present from a void. As an alternative to simply improving glass microballoon characterization and PETN pressing, the use of mono-size plastic microballoons offers good control of void size and eliminates the impedance mismatch. Plastic microballoons will probably not, however, withstand the pressure of solvent-pressing of PETN; a gelled liquid (to prevent balloon separation) or paste explosive would provide a good test matrix.

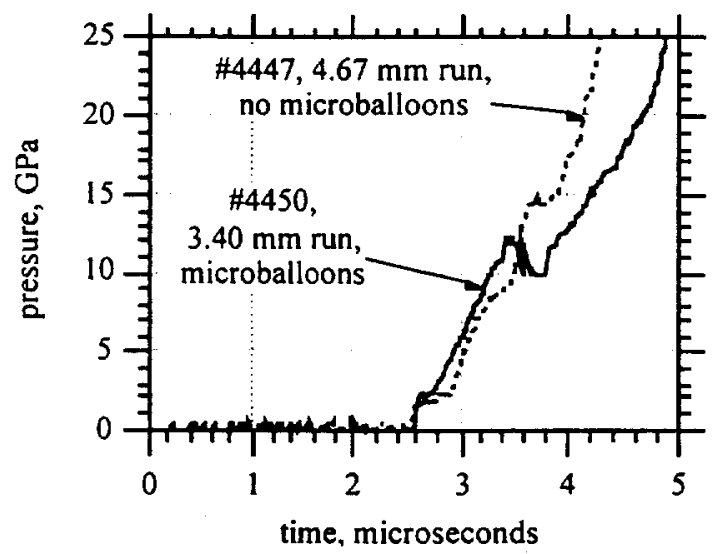

FIGURE 7. Data from the third pressure gauge with microballoons and fourth gauge without microballoons, 1.4 GPa.

\section{CONCLUSIONS}

We have demonstrated the practicality of embedding voids of known size and density into explosive, to characterize the effect of void density and size on shock initiation. The use of plastic microballoons and gelled or paste explosives offers improvements over the experimental system used here.

\section{ACKNOWLEDGMENTS}

We thank Jeffrey Wardell for his expert mechanical support of these experiments, and the HEAF gun crew for their role in firing the shots. This work was performed under the auspices of the U.S. Department of Energy by Lawrence Livermore National Laboratory under contract No. W-7405ENG-48.

\section{REFERENCES}

1. P.A. Urtiew, T.M.Cook, J.L. Maienschein, C.M. Tarver, "Shock Sensitivity of IHE at Elevated Temperatures," Proceedings Tenth International Detonation Symposium, July 1216, 1993, ONR 33395-12, p. 139. 


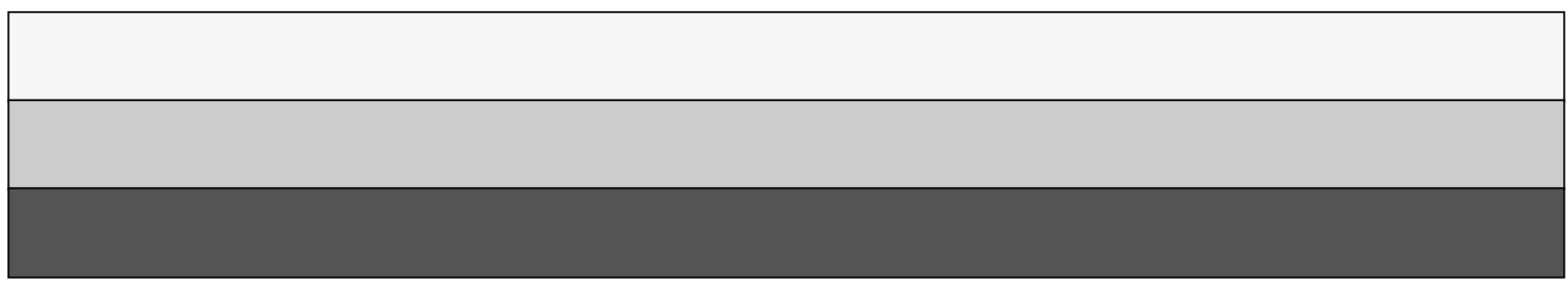

